\title{
LEYENDAS MONETALES, ICONOGRAFÍA Y LEGITIMACIÓN EN EL CALIFATO HAMMŪDÍ. LAS EMISIONES DE 'ALĪ B. HAMMŨD DEL AÑO 408/1017-1018
}

AlMUdena ARIZA ARMadA

Syracuse University Center in Spain

El presente trabajo ${ }^{1}$ tiene como objetivo el análisis de las acuñaciones del año 408/1017-1018 que llevara a cabo 'Alī b. Hammūd al-Hasanī, primer califa de la dinastía hammūdí en al-Andalus. Se trata de unas emisiones que cuentan con una serie muy característica y peculiar que hasta la fecha no ha sido analizada en profundidad, en la que aparecen representaciones figurativas animales.

Tras hacer una breve descripción del material estudiado, analizaré las características generales de los ejemplares del año 408/1017-1018, para detenerme, posteriormente, en el estudio de la serie de dicho año en la que encontramos el motivo iconográfico del pez. Por último, abordaré la problemática que plantea dicho recurso ornamental en las emisiones andalusíes y norteafricanas, sugiriendo una serie de hipótesis interpretativas y líneas de investigación que puedan llevarnos a un mejor conocimiento de la numismática hammūdí. Al final de este trabajo, podrá encontrarse el catálogo de los ejemplares con peces del año 408/1017-1018.

El estudio se ha realizado sobre un total de 248 ejemplares de 'Alī b. Hammūd, que son las piezas que de este califa se conservan en las principales colecciones públicas y privadas, tanto españolas como extranjeras ${ }^{2}$. La muestra es pues suficientemente importante como para

\footnotetext{
${ }^{1}$ Este trabajo es fruto de mi tesis doctoral titulada «Estudio sobre las monedas de los Hammūdíes de al-Andalus (s. V/XI)», que se encuentra en curso de realización.

${ }^{2}$ Las colecciones que he podido estudiar personalmente, además de algunas de particulares, y a cuyos fondos pertenecen los ejemplares analizados son: Museo Arqueológico Nacional (Madrid), Museo de la Casa de la Moneda (Madrid), Real Academia de la Historia (Madrid), Museo del Ejército (Madrid), Gabinete Numismático de Cataluña (Barcelona), Museo Arqueológico Provincial (Sevilla), Museo de Málaga, Bibliothèque Nationale (Paris), Musée de la Monnaie (Paris), British Museum (London), Ashmolean Museum (Oxford) y Fitzwilliam Museum (Cambridge). Me fue posible el estudio de los
}

Al-Qanțara XXV, 1 (2004) 203-231 
poder llegar a conclusiones significativas, no tanto quizá por el número de ejemplares en sí como por el hecho de que representan la inmensa mayoría de los que han llegado hasta nosotros. Abarcan una cronología que comprende desde el año 404/1013-1014 al año 408/1017-1018 ${ }^{3}$. La mayor parte de ellos son dirhames de buena ley frente a los tres dinares con los que contamos ${ }^{4}$. En cuanto a las cecas en las que fueron acuñados, están representadas al-Andalus y Madīnat Sabta, apareciendo esta última en ocasiones sin el apelativo de Madina.

De los 248 ejemplares estudiados, 103 son con seguridad del año $408 / 1017-1018$, lo que supone un $41,53 \%$ de la totalidad de los ejemplares; mientras que 6 de ellos son de fecha dudosa y bien podrían ser del año 407/1016-1017 o del 408/1017-1018.

Como evidencian los gráficos ( 1 y 2 ), la progresión anual en el porcentaje de ejemplares conservados es muy significativa. La rela-

fondos de las colecciones francesas y británicas indicadas gracias a las ayudas de investigación que me concedió la Agencia Española de Cooperación Internacional, Instituto para la Cooperación con el Mundo Árabe (ICMA) en los años 1991 y 1993. Además, están incluidas en el presente trabajo algunas colecciones cuyo acceso me ha sido imposible por diversos motivos, pero de las que he podido obtener información a través de diversas publicaciones; es el caso de la Colección de la American Numismatic Society (New York), Museo de Marsella, Museu Numismático Portugués, Museo Arqueológico de Córdoba y Museo Municipal de Sevilla. La información que precisaba sobre la colección del Museo Arqueológico y Etnológico de Granada, me fue facilitada por S. Peña Martín a quien desde aquí agradezco su colaboración.

${ }^{3}$ Prieto y Vives, A., Los Reyes de Taifas. Estudio histórico-numismático de los musulmanes españoles en el siglo V de la Hégira (XI de J.C.), Madrid, 1926, recoge un dinar del año 403/1012-1013, acuñado por 'Alī a nombre del califa Sulaymān (Prieto 53), posteriormente recogido en Rodríguez Lorente, J. J., Ibrāhīm, T., Numismática de Ceuta musulmana, Madrid, 1987, 77, $\mathrm{n}^{\circ} 2$; pero, dado que dicho ejemplar no se encuentra en las colecciones estudiadas, no lo he incluido en el presente estudio (véanse las notas $8 \mathrm{y}$ 10). Tampoco el ejemplar del año 441/1049-1050 en cuyo cuño aparece el nombre de 'Alī b. Hammūd y fue batido en la ceca de Wādī Law (A.N.S. 1978.36.3), ni los acuñados por soberanos taifas a nombre del califa hammūdí (véase a este respecto Ariza Armada, A., «Las cecas de Taifas bajo dominio eslavo», Rubartayr/Reverter 0, Gaceta Numismática, 105-106, Barcelona (1992), 143-164, con especial atención a la 147). Tampoco son objeto de este estudio, por merecer como en los casos anteriores tratamiento aparte, las imitaciones cristianas de las emisiones ḥammūdíes. Las siglas y abreviaturas utilizadas en este trabajo están detalladas en el catálogo de los ejemplares con peces que se ofrece al final del artículo.

${ }^{4}$ M.C.M. 15382 (Vives 732, Prieto 63a), M.A.N. 1958/3.44 (Vives 732, Prieto 63a), y IV Jarique, 7 (desconocido por Vives y Prieto). Prieto indica la existencia de un dinar del año 408/1017-1018 (Prieto 63c) que tampoco se encuentra en las colecciones estudiadas, como veremos más adelante. 
ción entre el aumento en la estabilidad de las emisiones y el aumento de la estabilidad política parece ser una constante en la historia de al-Andalus, que volvería a ponerse en este caso una vez más de manifiesto ${ }^{5}$. En una primera aproximación a los datos con los que contamos, parece posible deducir que la estabilidad lograda tras el acceso de 'Alī al poder califal podría quedar así patente en el porcentaje anual de sus emisiones ${ }^{6}$.

GrÁFICO 1.-Representación anual de los ejemplares de 'Alī b. Hammūd

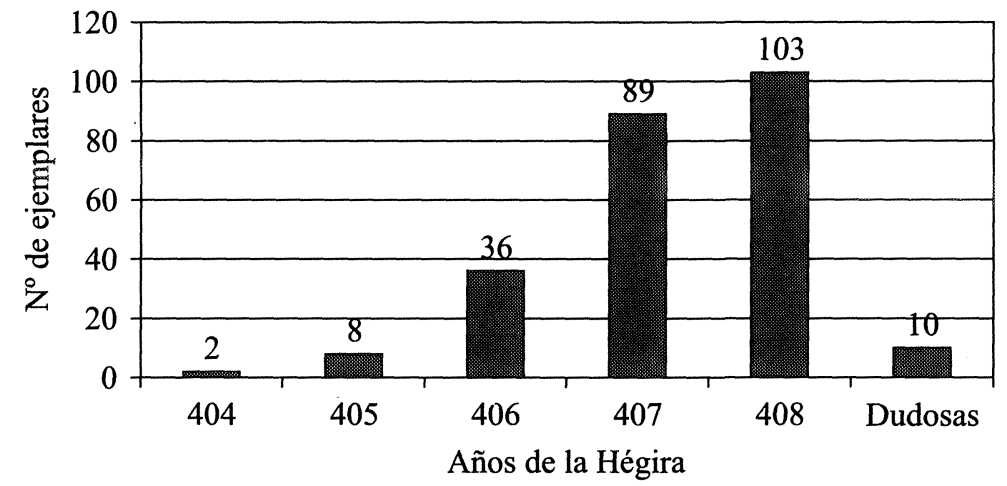

${ }^{5}$ Esta relación destaca especialmente en los momentos en los que la crisis política es mayor, llegando incluso a producirse «vacíos numismáticos» importantes. La falta de emisiones monetales durante largos períodos de tiempo fue ya destacada e interpretada por Guichard, P., «Quelques réflexions sur le monnayage des premières taifas andalouses (1009/400-1059/451)», II Jarique de Numismàtica Hispano-Arab, Lleida, 1990, 155161; «Los nuevos musulmanes», Historia de España, III, Barcelona, 1989, 448; véase también al respecto Ariza Armada, A., op. cit, y Ariza Armada, A., «Monedas en los reinos de Taifas», V Semana de Estudios Medievales, Nájera, 1995, 233-239.

${ }^{6}$ El constante número de nuevo tipos y hallazgos monetales que están saliendo últimamente a la luz, parece aconsejar mayor cautela si cabe a la hora de establecer una relación directa condicionante entre los volúmenes de ejemplares conservados y los índices de producción monetal, ya que el hecho de que ciertos ejemplares no se hayan conservado o no hayan llegado aún hasta nosotros, no implica necesariamente que no se acuñaran. Es más, para poder llegar a conclusiones realmente fiables al respecto, además de la valoración del número de ejemplares conservados, sería preciso realizar un estudio de hallazgos y de cuños, incluyendo éste último, como algunos autores ya han destacado, un análisis de la vida productiva de dichos cuños. $\mathrm{Al}$ respecto, véase por ejemplo Retamero, $\mathrm{F}$., "Fulüs y moneda en Mallorca, Ibiza y Menorca antes del 290 H./902 D.C.», Al-Qanțara, XVII (1996) 153-169. No obstante, con los datos con los que contamos hasta la fecha, esta relación causa-efecto parece clara. 
GrÁfICO 2.-Porcentaje anual de los ejemplares de 'Alī b. Ḥammūd

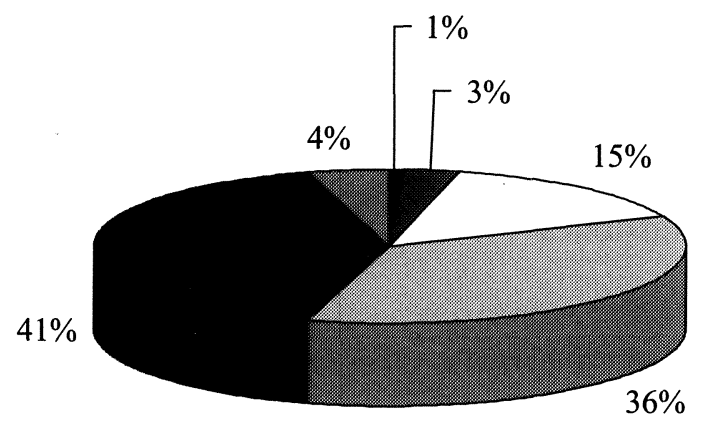

$404 \square 405 \square 406 \square 407 \square 408 \square$ Dudosas

\section{Los ejemplares del año 408/1017-1018}

Si analizamos los 103 ejemplares que se pueden catalogar con certeza como del año 408/1017-1018, comprobamos que, en primer lugar, aparentemente todos los ejemplares son dirhames de buena ley ${ }^{7}$; en segundo lugar, que frente a los escasos 8 ejemplares de la ceca peninsular, Madīnat Sabta está representada por 95 dirhames, lo que supone un $92,23 \%$ de las emisiones con las que contamos para este año; en tercer lugar, que de los 95 dirhames acuñados en Madinat Sabta, 8 tienen en su cuño la figura de dos o más peces, lo que supone un $8,42 \%$ de los dirhames ceutíes; y en cuarto y último lugar, que nunca aparece para este año el topónimo Sabta sin ir precedido del apelativo Madina.

En cuanto a las tipologías definidas por las leyendas monetales ${ }^{8}$, hay que indicar que de las emisiones del año 408/1017-1018 sólo coplares.

${ }^{7}$ Lamentablemente no ha sido posible realizar un análisis metalográfico de los ejem-

${ }^{8}$ Utilizo como referencia a Prieto y Vives, A., op. cit., por ser la principal obra específica para el período estudiado. Gran parte del trabajo de Wasserstein, D. J., The Caliphate in the West. An Islamic Political Institution in the Iberian Peninsula, Oxford, 1993, está dedicado a demostrar que esta obra carece de valor (cf. 5-6), básicamente, por no tra- 
nocemos dos series: la definida por el tipo Prieto $62 \mathrm{~b}$, al que corresponden el $92,23 \%$ de los ejemplares estudiados, y la del tipo Prieto $63 \mathrm{c}$ y $63 \mathrm{~d}$; a este último responden el $7,77 \%$ de las piezas con las que contamos.

El tipo Prieto $62 \mathrm{~b}$ se caracteriza por la siguiente distribución de leyendas en sus áreas:

I.A.

II.A.
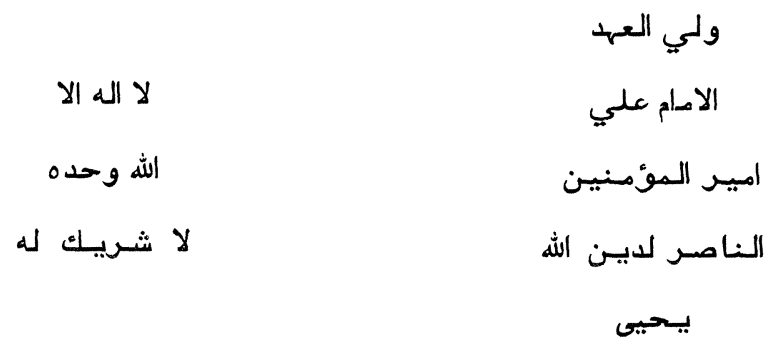

Este tipo se acuñó exclusivamente en la ceca Madinat Sabta, para los dirhames. La misma leyenda y distribución en el área aparece el año 407/1016-1017, para la misma ceca y metal (Prieto 62a).

tarse de un catálogo propiamente dicho y por considerar que las aportaciones de Prieto no deben ser tenidas como ciertas al no haber podido contrastarlas (cf., por ejemplo, 202), por desconocer la localización de los ejemplares en cuestión. Sin embargo, dichos ejemplares existen, aunque no se encuentren en las colecciones por él consultadas (cf. X). En lo que respecta a las series de 'Alī b. Hammūd, que son las que ahora nos ocupan y han sido mostradas como prueba en su juicio de valor (cf. 203), he podido consultar la constancia gráfica de la existencia de todos los tipos hammūdíes descritos por Prieto. De algunos, él mismo publicó imagen (por ejemplo, Prieto 53, lám. 3). Este material está siendo estudiado en el marco del proyecto 06/0131/2002 de la Comunidad de Madrid, Estudio y clasificación del material gráfico numismático de colecciones de Madrid, bajo la dirección de A. Canto, a quien agradezco las facilidades que me ha brindado para su análisis. En cuanto a que no se trate de un catálogo propiamente dicho, la obra de Prieto nunca pretendió serlo. En mi opinión, es precisamente en ello donde radica su valor, al tratase del primero - y hasta la fecha, único- ensayo de sistematización de tipologías para el período estudiado. A pesar de sus limitaciones (como la de no indicar la localización de los ejemplares que describe), sus aciertos la convierten en una valiosa e imprescindible aportación a la numismática andalusí (véase, por ejemplo, infra, 211). 
En el tipo Prieto 63c y 63d, podemos leer:

I.A.

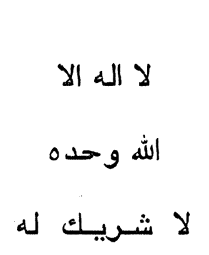

II.A.

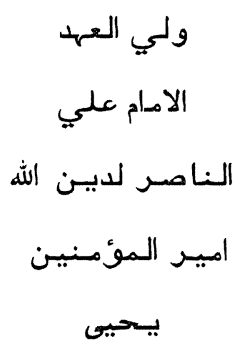

Este tipo se acuñó en al-Andalus en los mismos años que el anterior, 407/1016-1017 y 408/1017-1018, pero no solamente en plata sino también en oro ${ }^{9}$. Es significativo el hecho de que esta serie áurea se acuñara sólo en al-Andalus y no - por lo que sabemos - en la ciudad de Ceuta ${ }^{10}$. Estas emisiones pueden considerarse como un indicio más de legitimación ${ }^{11}$ tras su acceso al poder, al hacer uso de la prerrogativa califal de acuñar oro, y de hacerlo en Córdoba, la capital del Estado.

Es sabido que 'Alī, al ser proclamado califa, «tomó los sobrenombres sultánicos de an-Nāṣir li-Dīn Allāh, sobrenombre con el que [ya] le habían precedido otros» ${ }^{12}$. Como ya se ha destacado, que el laqab que tome el hāšimí sea el mismo que anteriormente tomara 'Abd al-Raḥmān [III], primer califa omeya de al-Andalus, no es en absoluto un hecho casual. 'Alī no destaca su ascendencia šī'í, ni hace alusión a los idrīsíes o a los 'abbasíes en sus leyendas monetales ${ }^{13}$, sino

\footnotetext{
9 Véase en la nota 4 lo referido a Prieto 63c.

10 Como ya he indicado (nota 3), se conoce un solo ejemplar de dinar acuñado en Ceuta el año 403/1012-1013 a nombre de Sulaymān y anterior a su proclamación como califa (Prieto 53, Ceuta 2), por lo que no afecta a la cuestión que abordamos ni altera el planteamiento. Sobre los problemas que plantea esta serie áurea, que analizo en profundidad en mi tesis doctoral, cfr. la p. 54 de Acién Almansa, M., «Los ḥammūdíes, califas legítimos de Occidente en el siglo XI», Actas del Congreso De Toledo a Huesca. Sociedades medievales en transición a finales del siglo XI (1080-1100), Zaragoza, 1998, 45-59.

11 Diversos aspectos de su legitimidad han sido argumentados a través del análisis de diferentes fuentes por Acién Almansa, M., op. cit.

12 Ibn 'Id̄ārī, La caída del Califato de Córdoba y los Reyes de Taifas (al-Bayān al-Mugrib), estudio, trad. y notas F. Maillo Salgado, Salamanca, 1993, 110.

${ }_{13}$ Alusiones que sí realizarán posteriormente algunos de sus sucesores. Véase al respecto Clément, F., Pouvoir et légitimité en Espagne musulmane à l'époque des taifas (Ve-XI siècle). L'imam fictif, Paris, 1997, 251.
} 
que se refiere explícitamente a la dinastía omeya; y no a cualquiera de sus miembros, sino al que fuera el primer califa de al-Andalus. Su voluntad de continuidad con el califato de Córdoba parece, por tanto, diáfana ${ }^{14}$.

Pero, en mi opinión, la trascendencia de este recurso legitimatorio tiene otras vertientes. Como consecuencia directa queda equiparada su propia dinastía a la omeya, y él mismo como primer califa 'alawí al primer califa omeya, y 'Alī al-Nāṣir b. Hammūd, «primero de los reyes (mulūk) Banū Hāšim en al-Andalus»» ${ }^{15}$ se convierte así en el primer soberano hāšimí que porta el título de imām - no sólo en la práctica sino también en el protocolo- como lo hace constar en el cuño de sus monedas. Aunque algunos soberanos idrīsíes habían aparecido ya intitulados como imämes en algunas inscripciones epigráficas y parece que podría tratarse de un hecho cotidiano respondiendo a la concepción šî'í del imamato, en tanto que príncipes soberanos descendientes de 'Alī b. Abī Țālib, dicho título estaba reservado en el protocolo idrīsí a los califas 'abbasíes de Bagdad ${ }^{16}$. Hecho corroborado por la numismática: los distintos miembros de la dinastía idrīsí que ejercieron el poder nunca aparecieron como imāmes en el cuño de sus monedas.

Como destacó H. Ferhat, refiriéndose a 'Alī b. Hammūd: «ll faut noter que le prince de Tanger et de Sabta ne tente pas de s'emparer de Fès, capitale des ancêtres et ne montre aucun désir d'intervenir dans le reste du Maghreb. Seule Cordoue, siège du califat, l'intéressait. Les Banū Hammūd (...) ne revendiquent pas leur héritage légitime, ne mettent pas en avant leur qualité de "šarîf". Ils se présentent au contraire comme les héritiers du calife de Cordoue. Le Sharifisme, qui deviendra au Maroc, le premier critère du pouvoir, ne s'est pas encore développé» ${ }^{17}$. Partiendo de esta última afirmación, podríamos dar un

14 El papel de 'Alī b. Ḥammūd como «defensor de la más pura legitimidad omeya» (Acién Almansa, M., op. cit., 50) fue ya señalado por Wasserstein, D. J., The Rise and Fall of the Party Kings. Politics and Society in Islamic Spain 1002-1086, New Jersey, 1985, 70, y The Caliphate in the West, 30-31 y 50-51.

${ }^{15}$ Ibn 'Id̄ārī, op. cit., 108.

16 Sirva como ejemplo Dāwūd b. Idrīs, que aparece como al-Imām en la inscripción fundacional de una pequeña mezquita. Véase Eustache, D., Corpus des Dirhams Idrisites et Contemporains. Collection de la Banque du Maroc et autres collections mondiales, publiques et privées, Rabat, 1970-1971, 51. Otras consideraciones relacionadas con el šíísmo de la dinastía hammūdí serán tratadas más adelante.

17 Ferhat, H., Sabta. Des origines au XIV ime siècle, Rabat, 1993, 85. Sobre otras cuestiones relacionadas con el šarifismo, consúltese Kably, M., Société, pouvoir et reli- 
paso más enfocando la cuestión desde otra perspectiva. Es decir, preguntándonos hasta qué punto, el hecho en sí de que un príncipe hāšimí portara por primera vez el título de califa fue determinante $y / 0$ en qué medida influyó en el desarrollo posterior del šarífismo.

A este respecto, cabe destacar dos cuestiones más. En primer lugar, el hecho de que en este acto simbólico concreto de legitimación de poder, en vez de poner en primer plano su condición de šarif ${ }^{18}$ destaque su vinculación a la dinastía omeya que le precede, no parece implicar necesariamente que su pertenencia a la familia del Profeta no fuera decisiva, tanto en su pretensión al califato cordobés, como en el hecho de que su dinastía mantuviera el poder califal como el mayor poder estable del momento ${ }^{19}$. En segundo lugar, si aceptamos que el califato es, en su planteamiento teórico, una institución única para toda la Där al-Isläm ${ }^{20}$, podemos concluir que la aspiración de 'Alī al-Nāṣir a ser califa de al-Andalus conlleva su aspiración de poder sobre el Magreb. Si ser califa de Córdoba era ser califa de Occidente y, al igual que para muchos otros aspectos, al-Andalus y el Magreb son concebidos como una misma área, el occidente islámico (al-garb al-islämī), desde el punto de vista del poder califal la situación no tiene por qué ser diferente en los presupuestos ideológicos de los aspirantes al califato. Por tanto, su pretensión al califato cordobés no tiene por qué implicar una falta de interés por el Magreb, sino incluso bien al contrario, podría entenderse como una vía de legitimación, el primer paso para que la dinastía 'alawí pudiera ejercer el poder como califas legítimos sobre unos territorios que sus ancestros idrīsíes habían regido sujetos a la autoridad — al menos nominal — del califa de Bag-

gion au Maroc a la fin du «Moyen-âge», Paris, 1986, especialmente 291-302; y Beck, H. L., L'Image d'Idris II, ses descendants de Fas et la politique sharifienne des sultans marinides (656-869/1258-1465), Leiden, 1989.

18 Ascendencia que de hecho le perjudica y que ha sido utilizado en su contra tanto por las fuentes andalusíes - Ferhat, H., op. cit.- como por la historiografia española del primer tercio del s. XX - valgan como ejemplos Seco de Lucena, L., Los hammüdies, señores de Málaga y Algeciras, Málaga, 1955.

19 Aun cuando accediera al poder como líder de los beréberes y no como šarîf (cf. Wasserstein, D. J., The Caliphate in the West, 51), no parece haber otra razón, salvo su ascendencia, que explique tal liderazgo. Véase: Ibn 'Idârī, op. cit., 103-104 y 108; Acién Almansa, M., «Málaga Musulmana (s. VIII-XIII)», Historia de Málaga, Málaga, 1994, 221; p. 497 de «De la conquista musulmana a la época nazari», Málaga, t. II: Historia, Granada, 1984, 469-510; y «Los hammūdíes, califas legítimos», 49-50. Sobre genealogía hammūdí: Wasserstein, D. J., The Caliphate in the West, 50 y ss.

20 Acién Almansa, M., «Los ḥammūdíes, califas legítimos», 48-49. 
dad. De ser así, 'Alī al-Nāṣir b. Hammūd habría dado el primer paso en el desarrollo del posterior šarifismo magrebí.

Volviendo a las leyendas que aparecen en el cuño de las monedas del año 408/1017-1018, otro aspecto importante que debe destacarse es la significativa alteración que se produce en la distribución de la leyenda central de la segunda área. Será A. Prieto el primero en recoger en su obra el nuevo tipo ${ }^{21}$. Desde entonces no ha vuelto a pasar desapercibida.

Se trata de una alteración por la cual, en las emisiones peninsulares, prevalecerá en el orden de la leyenda el título de al-Nāsir li-Dìn Alläh frente al de amī al-mu'minin. Cabe por tanto preguntarse la razón por la que, de todos los tipos acuñados para todos los años de su imāmato, las únicas piezas en las que antepone su laqab a su título de amir sea en las acuñadas en la ceca de al-Andalus. O quizá habría que plantear la pregunta desde otra perspectiva: ¿por qué en las piezas acuñadas en Ceuta antepone su título de amir al-mu'minin a su laqab, rompiendo así la expresión completa de su nombre? Dicho en otras palabras: ¿en qué monedas es en las que se produce realmente tal alteración, en las de al-Andalus o en las de Ceuta?

En primer lugar, cabe señalar que el hecho de que en los mismos años (407/1016-1017 y 408/1017-1018) se estén acuñando piezas en ambas cecas, parece descartar la sucesión cronológica en las emisiones como posible explicación a esta alteración.

Por otro lado, si analizamos la distribución de las leyendas de las emisiones de 'Abd al-Raḥmān [III], que son la referencia obligada, encontramos que en todos los tipos del primer califa de Córdoba 22 aparece en primer lugar su laqab, y siempre en último término el título de amìr al-mu'minīn. Es decir, 'Alī b. Hammūd no sólo utiliza el laqab califal indicado, sino que reproduce en sus emisiones andalusíes el mismo orden en la distribución de las leyendas monetales que utilizara el primer califa omeya. Acto de altísimo valor simbólico si

${ }^{21}$ Además de señalarlo en su estudio: Prieto y Vives, A., op. cit., 109. No obstante, A. Delgado lo había hecho notar en su obra manuscrita, recientemente editada, que ya había comenzado a redactarse en 1851: Delgado, A., Estudios de numismática arábigo-hispana considerada como comprobante de la dominación islámica en la península, $\mathrm{A}$. Canto García y T. Ibrāhīm (eds.), Madrid, 2001, 155. Sobre la cronología de esta obra cf. XVII-XXV.

${ }^{22}$ A excepción de los tipos Vives 377 y 379-382, que comparten la leyenda de la II.A. y son todos tercios de dinar sin ceca. Estos tipos no son valorables en nuestro planteamiento ya que en ellos aparece sólo el ism del califa y no su laqab. 
tenemos en cuenta que seguir este mismo orden supone romper con la tradición que han seguido todos los califas que sucedieron en el imāmato a 'Abd al-Raḥmān [III], que destacan en primer lugar su título de $a m i \bar{r}$ y después su laqab ${ }^{23}$. Por tanto, se trata de un acto premeditado y puntual, que afecta sólo a sus emisiones andalusíes. Éstas representan así una excepción respecto a lo que se venía haciendo, que parece tener el objetivo expreso de seguir las pautas marcadas por el primer califa omeya, reafirmando así su legitimidad. Excepción a la que dará continuidad su sucesor al-Qāsim al-Ma'mūn, tanto en sus emisiones peninsulares como en las ceutíes.

Cabe por tanto preguntarse por qué se produce este cambio sólo en la ceca de al-Andalus, y por qué se mantiene el orden de distribución de las leyendas en las emisiones de la ceca de Ceuta, en vez de ajustarlas al modelo que se ha introducido en las acuñaciones peninsulares. Parece razonable pensar que se está poniendo de manifiesto la necesidad de reafirmación de su legitimidad, ante un pueblo -el andalusí- más reacio a aceptar su autoridad que el magrebí ${ }^{24}$. Es decir, que en territorio peninsular, no basta sólo con indicar su derecho al califato sino que hay que hacerlo destacándolo con evidencia. Es más, poniendo de relieve su título de al-Nāṣir li-Dīn Allāh, está desmarcándose ante la población andalusí de cualquier sospecha de ší'ísmo radical o relación con los fatimíes ${ }^{25}$. Por el contrario, en Ceuta no fue necesario introducir dicha variación porque no debió existir tal rechazo por parte de la población. En el Magreb, su derecho al califato no se ponía en tela de juicio. La moneda se evidencia, una vez más, como instrumento de propaganda política y como testimonio plástico de los actos simbólicos de legitimación.

${ }^{23}$ Salvo muy contadas excepciones que dejan abierta una interesante línea de investigación.

${ }^{24}$ Como ya se ha indicado, queda constancia en las fuentes escritas de este recelo por parte de los andalusíes.

${ }^{25}$ No hay que olvidar que 'Abd al-Raḥmān [III], al tomar el título de al-Nāssir li-Dīn Allāh, se erigía en el defensor del Islam sunní en occidente frente a los fatimíes. Sobre las características del ši' 'ísmo en al-Andalus: Fierro, M. I. La heterodoxia en al-Andalus durante el periodo omeya, Madrid, 1989, y «Espacio sunní y espacio šíi'i», El esplendor de los Omeyas cordobeses. La civilización musulmana de Europa Occidental. Estudios, Granada, 2001, 168-177; concretamente, respecto a la dinastía hammūdí: Fierro, M. I., «La religión», Los Reinos de Taifas. Al-Andalus en el s. XI, Historia de España Menén-

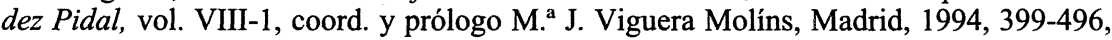
especialmente $435-437$. 
Por último, hay que destacar que en todas las series de 'Alī, ya como califa, se hace mención a su hijo Yaḥyà en el cuño monetal. Salvo en un caso (Prieto 60) en el que figura sólo con su nombre, en todos los tipos restantes aparece especificado su título de («heredero») 26. La voluntad de continuidad dinástica se resalta significativamente en todos los ejemplares de las series de al-Nāșir, hecho que no debería ser pasado por alto a la hora de valorar sus emisiones.

\section{Los ejemplares del año 408/1017-1018 con peces}

Como he indicado anteriormente, los ejemplares de 'Alī al-Nāṣir en los que aparecen representadas figuras de peces son 8 , frente a los 87 restantes de la ceca de Madinat Sabta. Ello supone un porcentaje del $8,42 \%$ respecto al total de las emisiones de la ceca, durante este último año del gobierno de 'Alī. Aunque, a simple vista, puedan parecer de escasa importancia debido a su reducido número, hay que tener en cuenta que representan seis variantes decorativas diferentes $\mathrm{y}$, al menos, otras tantas variedades de cuño (véase el catálogo), con la trascendencia que ello tiene a la hora de valorar esta serie y sus posibles volúmenes de emisión.

En cuanto a las leyendas monetales, todos los ejemplares responden al tipo Prieto 62b, si bien cabe hacer una puntualización sobre la leyenda de la orla de la segunda área (II.M.). Para todos los tipos de las monedas hammūdíes, ésta se identifica con dos aleyas de idéntico contenido (Qur'ān IX, 33 y LXI, 9) aunque, como ya indicó G. C. Miles, se trata en realidad de una adaptación del texto coránico que no altera básicamente su sentido ${ }^{27}$. Que se trate de una adaptación es, a mi parecer, sumamente significativo ya que corrobora la idea, sobre la que abundaré más adelante, de la importancia de la moneda como instrumento de propaganda religiosa: la modificación del texto coránico pone de manifiesto que lo realmente importante es la claridad en

\footnotetext{
${ }^{26}$ La problemática de la sucesión de 'Alī b. Hammūd es un tema clave, que ya se ha puesto en varias ocasiones sobre la mesa y he abordado con detenimiento en mi tesis doctoral, pero que no voy a tratar aquí por salirse del tema que nos ocupa.

${ }_{27}$ Miles, G. C., The Coinage of the Umayyads of Spain, Nueva York, 1950, 27, nota 1 .
} 
la transmisión del mensaje religioso, aun en detrimento de la fidelidad al texto sagrado.

\section{El motivo figurativo del pez}

Quizá lo más llamativo de las series del año 408/1017-1018 sea la aparición de motivos figurativos en el cuño de algunos de sus ejemplares, es decir, la representación de peces. Este hecho, a mi parecer de radical importancia, no ha sido aún analizado en profundidad por la historiografía que ha tratado el tema. Ni A. Vives ${ }^{28}$ ni A. Prieto ${ }^{29}$ mencionaron la existencia de peces en las monedas hammūdíes. Hacia 1851, A. Delgado destacó escuetamente la aparición de «pececillos» como adornos en las monedas ceutíes ${ }^{30}$. En 1877, F. Codera señalaba la profusión de adornos existentes en las monedas ceutíes de 'Alī b. Hammūd, en comparación con los que podemos encontrar en las acuñadas en al-Andalus por el mismo imām, e identificaba los peces con atunes ${ }^{31}$. Tres años después, F. Guillén Robles se hizo eco de la existencia de dicho motivo decorativo destacando su gran rareza ${ }^{32}$. Posteriormente, en 1954, G. C. Miles recogió un ejemplar de este tipo (Miles, 30) pero no hizo observación ni valoración alguna al respecto ${ }^{33}$. J. M. Navascués, en 1956, realizó una detallada descripción de los ejemplares con peces del M.A.N., aunque sin entrar tampoco en valoraciones sobre el tema ${ }^{34}$. Habrá que esperar a 1987 para encontrar, hasta la fecha ${ }^{35}$, la primera y única valoración que intente explicar la aparición de este peculiar motivo figurativo: J. J. Rodríguez Lo-

28 Vives, A., op. cit.

29 Prieto, A., op. cit.

30 Delgado, A., op. cit., 155.

31 Codera y Zaidin, F., «Estudio crítico sobre la historia y monedas de los Hammudíes de Málaga y Algeciras», Museo Español de Antigüedades, VIII (1877), 431.

32 Guillén Robles, F., Málaga musulmana-Sucesos, antigüedades, ciencias y letras malagueñas durante la Edad Media, Málaga, 1957 (1. a edición, 1880), 242.

${ }_{33}$ Miles, G. C., Coins of the Spanish Mulük al-Tawä'if, Nueva York, 1954, 9.

34 Navascués y de Palacio, J. M., Catálogo de las monedas de los Reyes de Taifas en España (s. XI) existentes en el Museo Arqueológico Nacional. Memoria de Licenciatura inédita. Asesor Emilio García Gómez. Junio 1956.

35 A pesar de haberse realizado en los últimos años valiosos estudios sobre los hammūdíes o con referencias a ellos. Sirvan como ejemplo los trabajos ya citados de M. Ácién, F. Clément y D. Wasserstein, o el de Mora Serrano, B., Estudio de la moneda Hammūdi en Málaga. El hallazgo de dirhames de Ardales, Málaga, 1993. 
rente y T. Ibrāhīm indicaban que "estos "atunes" que aparecen en nuestros Nos. 38 y 39, nos recuerdan la importancia de esta industria en Ceuta desde la época fenicia. Las dos monedas son casos rarísimos de arte figurativo en dinares o dirhemes de esa época» ${ }^{36}$.

Efectivamente se trata de casos rarísimos, y por tal condición urge una valoración detenida al respecto y la búsqueda de una razón que justifique tal recurso ornamental, cuya trascendencia, desde mi punto de vista, va más allá de un mero interés decorativo.

\section{Antecedentes}

En primer lugar cabe señalar que la aparición de motivos figurativos en las monedas andalusíes no es nueva. Ya en las primeras monedas que circularon en al-Andalus podemos encontrar representaciones iconográficas tales como estrellas o peces. Estos últimos son el único antecedente iconográfico a las representaciones figurativas que aparecen en el cuño de las series del año 408/1017-1018 que nos ocupan. Tradicionalmente, la historiografía que ha abordado el tema de la representación de peces en las primeras monedas andalusíes, y más concretamente en los feluses del período de los gobernadores, se sitúa en la misma línea interpretativa que para las emisiones hammūdíes indicaran J. J. Rodríguez Lorente y T. Ibrāhīm, haciendo entroncar estos tipos con la tradición local ${ }^{37}$.

${ }^{36}$ Rodríguez Lorente, J. J., Ibrāhīm, T., Numismática de Ceuta, 84.

37 Rodríguez Lorente, J. J., Ibrāhīm, T., op. cit. Se trata de los trabajos de Navascués y de Palacio, J. M., «Estudio de Numismática musulmana occidental», Numario Hispánico, VII (1958), 49-50 (graf. 4 a 7) y «Los sueldos hispano-árabes. Catálogo de las primitivas monedas arábigo-españolas que se guardan en el Museo Arqueológico Nacional y en el Instituto Valencia de D. Juan en Madrid, Numario Hispánico, VIII (1959), 5-66; Barceló Perelló, M., «Sobre algunos fulūs contemporáneos a la conquista de Hispania por los árabe-musulmanes», Boletín de la Real Academia de Buenas Letras de Barcelona (1972), 33-42 y «Els fulūs de Tanğa de finals del segle I H./VII d.C., els pactes més antics i el cas de Mallorca i Menorca: una revisió», Gaceta Numismática, 114 (septiembre de 1994), 5-18, así como «Correccions a "Els fulūs deTanğa de finals del segle I H./VII d.C., els pactes més antics i el cas de Mallorca i Menorca: una revisió"», Gaceta Numismática, 115 (diciembre de 1994), 63-64; Balaguer, A. M., Las emisiones transicionales árabe-musulmanas de Hispania, Barcelona, 1976 y Acta Numismática, 30 (2000); Morgenstern, R., «Un "fals" con pez inédito», Symposium Numismático de Barcelona, I, 1979, 531-534; y más recientemente, los trabajos de Frochoso Sánchez, R., «Los feluses del período de los gobernadores omeyas en al-Andalus», Numisma, 237, enero-junio (1996), 259-289, «Los Feluses del emirato independiente», Numisma, 239, enero-ju- 
En 1976, A. M. Balaguer, siguiendo las tesis de J. M. Navascués y M. Barceló, en su clasificación de la moneda transicional, consideraba la tipología del pez como una «imitación de un tipo monetario preexistente en la zona del Estrecho» ${ }^{38}$, respondiendo a una «simbología local relacionada con las actividades pesqueras de la zona del Estrecho» ${ }^{39}$. En 1979, R. Morgenstern, siguiendo los trabajos anteriores, abundaba ampliamente en la relación del uso de la iconografía del pez en los feluses transicionales con la importancia de la pesca del atún en el Estrecho de Gibraltar ${ }^{40}$. Por último, en 1996 y siguiendo los trabajos de J. M. Navascués ${ }^{41}$, R. Frochoso situaba cronológicamente dichas emisiones en el momento previo del paso de Tāriq a la Península Ibérica, atribuyendo su acuñación a la ceca de Tánger y destacando su continuidad iconográfica respecto a las emisiones hispanas o africanas del Estrecho. Aportaba, en relación a la historiografía anterior, la idea de que la representación monetal se pudiera identificar, más que con atunes, con los esturiones, especie conocida desde antiguo en el río Guadalquivir ${ }^{42}$.

Personalmente, considero que este planteamiento de continuidad iconográfica al que se ha aferrado la historiografia que ha tratado el tema es, cuanto menos, cuestionable. En primer lugar, la importancia de la pesca como argumento para fijar la acuñación de estos feluses en al-Andalus, por mucho que se asocie al símbolo de la estrella, no deja de plantear interrogantes ${ }^{43}$. En segundo lugar, no hay que olvidar que la importancia de la pesca no se da sólo en el Estrecho de Gi-

nio (1997), 9-73, y Los feluses de al-Andalus, Madrid, 2001. La aportación de Bates, M. L., "The coinage of Spain under the Umayyad caliphs of the east», III Jarique de Numismática Hispano-Árabe, Madrid, 1993, 271-290, es fundamental, pero no aborda la temática del pez, ni hace por tanto, reflexiones o valoraciones al respecto. Consideraciones sobre esta línea historiográfica, pueden verse en Ariza Armada, A., "Aniconismo e iconografia monetal en al-Andalus», Primer Simposio España y Estados Unidos. Una mirada desde el Instituto Internacional, ed. A. Janzon, Madrid, 2001, 23-33.

${ }^{38}$ Balaguer, A. M., Las emisiones transicionales, 71.

39 Ibidem, 21.

40 Morgenstern, R., «Un "fals" con pez», 531.

${ }^{41}$ Navascués y de Palacio, J. M., «Estudio de Numismática musulmana».

42 Idea que, vinculada a la de la aparición de estrellas y a la identificación de éstas como un símbolo propiamente hispano, argumenta la teoría de que se trate de acunaciones peninsulares en lugar de magrebíes. Frochoso Sánchez, R., «Los feluses del período de los gobernadores», 261-262 y Los feluses de al-Andalus, 19-20.

${ }_{43}^{4} \mathrm{La}$ estrella no es un símbolo exclusivo del Mediterráneo Occidental, ni concretamente de Hispania. La importancia de su valor en la iconografia monetal islámica merece un estudio detenido, que me propongo realizar en próximos trabajos. 
braltar o en la cuenca del Guadalquivir, sino que el pescado ocupó un lugar predominante en la dieta de las poblaciones musulmanas, que ha sido una de sus fuentes de alimentación, y no sólo en el Mediterráneo, hasta el punto de ser objeto de disposiciones judiciales concretas ${ }^{44}$. Por tanto, es un símbolo que encaja perfectamente en el contexto oriental y no es exclusivo de la zona del Estrecho. Y en tercer lugar y en esta misma línea, si aceptamos las cronologías propuestas, no hay que pasar por alto que coetáneamente se están acuñando feluses con peces en las cecas de la "Gran Siria» (Biläd al- $\breve{S} \bar{a} m$ ), desde un punto de vista estilístico muy similares a los feluses supuestamente tangerinos o andalusíes. Ni menos aún el hecho de que fuera un contingente militar de la circunscripción siria de Emesa (Himș) - donde ya se estaban acunando feluses con peces- el que recibió concesiones para su asentamiento en los territorios del Guadalquivir. Por tanto, desde mi punto de vista y aun cuando aceptáramos que realmente se acunaran en Tánger o en al-Andalus, es quizá en el contexto sirio-oriental en el que deberían englobarse este tipo de emisiones más que en un contexto local, ya que responden al espacio simbólico de la mentalidad de la nueva comunidad establecida en la Península; comunidad que no parece tener gran intención de continuidad respecto a los espacios simbólicos precedentes, por lo menos en lo que a al-Andalus se refiere ${ }^{45}$.

Con posterioridad a estas emisiones tempranas, no vuelve a darse en al-Andalus ningún otro caso de representaciones figurativas de seres vivos en el cuño de las monedas, ya sean éstas de oro, plata o bronce, hasta que en el año 408/1017-1018 aparezcan las emisiones de 'Alī b. Hammūd que nos ocupan. Considero que, al menos en el caso de al-Andalus, la lectura de esta desaparición absoluta de toda representación de seres vivos a favor de la tipología puramente epigráfica introducida por la reforma omeya ${ }^{46}$, hay que hacerla sobre las bases de un afán de continuidad y fidelidad a los planteamientos de

44 Véase Viré, F., «Samak», $E I^{2}$, VIII, 1020-1023; sobre su consumo en al-Andalus: Torres, M. P., «El pescado en la gastronomía árabe mediterránea: al-Andalus», en Pérez Jiménez, A. y Cruz Andreotti, G. (eds.), Dieta mediterránea: comidas y hábitos alimenticios en las culturas mediterráneas, Madrid, 2000.

45 Ariza Armada, A., «Aniconismo e iconografia monetal», 27-30.

46 Sobre la reforma monetal omeya véase Gierson, P., «The Monetary Reforms of 'Abd al-Mālik», Journal of the Economic and Social History of the Orient, 3 (1960), 241-264. 
dicha dinastía extinguida en oriente. Es decir, hay que interpretarla como un acto de identidad y legitimación dinástica, que se mantiene inalterable por todos los miembros de la dinastía omeya andalusí.

¿Por qué entonces 'Alī b. Hammūd, en el momento en el que parece haberse afianzado en su imāmato, recurrió al uso de esta iconografía monetal en sus emisiones si quería legitimarse en el poder, yendo en contra de los principios del aniconismo islámico mantenidos fielmente por sus predecesores en el califato cordobés, máxime cuando todos sus actos parecen ir dirigidos a entroncar con la dinastía que le precedió?

\section{La industria pesquera en el Estrecho de Gibraltar}

Como he indicado anteriormente, la valoración comúnmente aceptada sobre la aparición de peces en el cuño de los dirhames del año 408/1017-1018 se hace en relación a la importancia de la industria pesquera en ambas orillas del Estrecho de Gibraltar. Esta interpretación de la iconografía hammūdí se mantiene tanto en las publicaciones como en las corrientes de opinión en círculos especializados donde, concretamente, se explica esta iconografía como consecuencia de un año de excepcional abundancia pesquera ${ }^{47}$. Sin embargo, desde mi punto de vista, se trata de una interpretación que plantea demasiados interrogantes como para que pueda considerarse satisfactoria.

En primer lugar, habría que contrastar la importancia real de esa industria pesquera en la época que nos ocupa, ya que su esplendor en la Antigüedad no es garantía de esplendor en el siglo V/XI. Respecto a la orilla norte del Estrecho de Gibraltar, las fuentes árabes no parecen hacer especial mención a la pesca y sus derivados o industrias afines, en la que se convertiría en la capital del poder hammūdí en al-Andalus ${ }^{48}$. Aunque sin duda, la industria pesquera debió continuar durante

47 Teoría propuesta y defendida por T. Ibrāhīm en la Mailing list «Islamic Coins». Sobre este foro especializado en numismática islámica véase Ariza Armada, A., «Numismática andalusí en Internet», IV Jarique de Numismática Andalusí, A. Canto y V. Salvatierra (eds.), Jaén, 2001, 231-239, especialmente las 233-234.

48 Siguiendo los datos aportados por una de las obras de conjunto más recientes sobre la Málaga musulmana: Calero Secall, M. A., Martínez Enamorado, V., Málaga ciudad de al-Andalus, Málaga, 1995, 304 y ss. El estudio incluye la información aportada por Ibn Jurdaḍbih (s. IX), al-Iștajrī e Ibn Ḥawqal (s. X), e Ibn Sa‘īd (s. XIII). Sí se hace 
el período que nos ocupa, parece lógico pensar que no debió ser tan significativa como lo fuera en la Antigüedad. Sin embargo, en la costa sur del Estrecho de Gibraltar la industria pesquera sí debió seguir siendo suficientemente importante como para aparecer reflejada en los textos geográficos. Así, la información proporcionada por al-Anșārī, sirvió a J. J. Rodríguez Lorente y T. Ibrāhīm para fundamentar su explicación sobre la aparición de estos peces en las monedas ${ }^{49}$.

A pesar de ello, cabe preguntarse si podría justificarse dicha aparición en razón de esta pujante industria pesquera. Asimismo, si este hecho explicaría el que aparezcan en los cuños de las monedas batidas, no en la Península, sino en Madinnat Sabta, donde la importancia de esta industria parece ser mayor. Es decir, si un excepcional año de pesca ${ }^{50}$ justificaría la representación figurativa de peces en las monedas, rompiendo la línea de actuación continuista que parece seguir 'Alī b. Hammūd para legitimarse en el poder. Y lo que quizá sea aún más relevante: si, como ya he indicado, no se ha recurrido a representaciones figurativas durante todo el período en el que estuvo en el poder la dinastía omeya, si no se ha recurrido a símbolos alusivos a hechos tan decisivos para el Estado como pueda ser una gran victoria militar, ¿por qué habría de hacerse por un buen año de pesca?

Es más, esta introducción de una representación figurativa no sólo parece contradecir la política de continuidad con el califato omeya de Córdoba llevada a cabo por el 'alawí, sino que supone también una ruptura con la tradición marcada por las emisiones magrebíes inmediatamente precedentes, como vamos a pasar a ver a continuación.

\footnotetext{
mención a la intensa actividad pesquera de Bezmiliana (al-Idrīsī, Nuzha, 202 y al-Himyarī, Raw $d$ al-Mictär, 44), pero al-Idrīsī omite esta industria al referirse a Almería, el puerto más rico de la zona (Geografia de España, 188). En cambio, las fuentes sí destacan las exportaciones de productos agrícolas, fundamentalmente de higos y almendras, y la pujanza de la industria de la sedería, la de tenerías y la alfarera (cf. Calero Secall, $\mathrm{M}$. A., Martínez Enamorado, V., op. cit., 307-308 y Guillén Robles, F., op. cit., 290-294 y 337-346).

49 Rodríguez Lorente, J. J., Ibrāhīm, T., op. cit., 21.

50 Excepcional año del que no parece quedar constancia: no he encontrado, ni en fuentes geográficas ni en históricas, mención alguna al respecto.
} 


\section{Emisiones idrīsíes y emisiones omeyas norteafricanas. Aspectos iconográficos}

Considero que un punto clave para poder profundizar en el conocimiento de las emisiones hammūdíes es el estudio comparativo de éstas con las emisiones idrīíes, análisis que, por lo que sé, no se ha llevado a cabo hasta la fecha. Dos razones aconsejan dicha comparativa: en primer lugar, el que sean las acuñaciones idrīsíes, junto con las emisiones omeyas norteafricanas, el antecedente cronológico a las acuñaciones hammūdíes en el Magreb; y en segundo lugar, y quizá más importante, la filiación idrīsí de la dinastía hammūdí.

Tras realizar dicho análisis, no he encontrado ningún antecedente de representación figurativa animal ni en las emisiones magrebíes de los califas omeyas de al-Andalus, ni en las llevadas a cabo por la dinastía idrīsí. Se podría intentar explicar la ausencia de peces en las primeras, argumentando que ninguna de ellas se acuñó en una ceca costera; y en cuanto a las segundas, señalando que, de las veintitrés cecas que batieron moneda para la dinastía idrīsí sólo dos son localidades costeras, y de ellas sólo una se encuentra en el Estrecho de Gibraltar ${ }^{51}$. Sin embargo, hace inviable este planteamiento el hecho de que esas dos cecas costeras idrīsíes sean Tánger y Arcila y, precisamente a la ceca de Tánger es a la que la historiografía numismática española atribuye la autoría de los feluses con pez del período de los gobernadores. Si aceptamos que aquellos feluses se acuñaron realmente en Tánger, nos encontramos ante un antecedente que podría haber justificado la aparición de peces en la moneda idrīí́, si diéramos por válidos los argumentos que explican tal uso iconográfico por la importancia de la industria pesquera. Si durante el período idrīsí, por muy importante que fuera la pesca no se justificaba una representación iconográfica figurativa, ¿por qué habría de justificarse posteriormente, durante el gobierno de 'Alī al-Nāṣir b. Ḥammūd? Máxime cuando los ejemplares se baten en Ceuta, que es una ceca de nueva factura.

51 Sobre las cecas y ciudades idrīsíes véase Eustache, D., op. cit. y García-Arenal, M., Manzano Moreno, E. «Idrissisme et villes idrissides», Studia Islamica, 82 (1995), 5-31. 


\section{Hipótesis y líneas de investigación}

Como he puesto de manifiesto, creo que la respuesta al porqué de la aparición de peces en algunas emisiones ceutíes del año 408/10171018 no está en motivos de índole económico. Aunque quizá, hoy por hoy, no contemos con datos suficientes como para poder aportar una explicación concluyente, sí se pueden trazar las que considero líneas principales de investigación y plantear una serie de hipótesis que puedan conducir a un mayor conocimiento de las verdaderas razones que pudieron llevar al primer califa hāšimí a recurrir a semejante motivo iconográfico. Y no ya en la moneda de cobre, numerario subsidiario ${ }^{52}$, sino revalorizándolo, dignificándolo en emisiones de plata de bellísima y cuidada factura.

A la hora de intentar explicar la vuelta a una iconografía en uso durante la primera época del Islam, en un momento crítico en el que la institución califal está en juego, quizá la clave esté en distinguir hasta que punto la iconografía del pez podría considerarse un símbolo oriental ${ }^{53} \mathrm{o}$ más bien un símbolo local entroncado por tanto, de alguna manera, con la tradición beréber.

Si lo consideramos un símbolo oriental, teniendo en cuenta que se produce una ruptura en cuanto a las leyendas con los califas precedentes y parece buscarse como vía de legitimación el marcar un paralelo con las emisiones de 'Abd al-Rahmān [III], la introducción de esta iconografia, junto con la proliferación de elementos decorativos de otra índole, podría entenderse como un elemento de diferenciación dinástica frente a los omeyas cordobeses, superando los principios anicónicos de la reforma de 'Abd al-Mālik.

Por otro lado, es un hecho comúnmente aceptado el considerar a los hammūdíes como una dinastía «berberizada». Así pues, si lo consideramos un símbolo local, aún incluso no por su origen sino por su arraigo, bien pudiera ser la expresión de esa influencia beréber que le atribuyen las fuentes árabes. Y en esta misma línea, el uso de dicho símbolo podría entenderse como la expresión plástica del poder otor-

52 Barceló Perelló, M., «Sobre algunos fulūs», 39.

53 Cabría plantearse también si podría responder a pautas generales que se estuvieran dando en paralelo en otros territorios de la Dār al-Islām. A este respecto, no conozco ninguna representación similar en monedas contemporáneas en ningún otro territorio islámico. Se trata por tanto de ejemplares, si cabe, aún más excepcionales. 
gado nuevamente a la comunidad beréber, tras haberla sometido duramente en los momentos inmediatos a su acceso al poder ${ }^{54}$.

Por último, quisiera plantear otra hipótesis interpretativa, que no estaría ya relacionada con el ámbito del poder político, sino más bien con el de la espiritualidad. Moviéndonos en esta esfera, la introducción de un tipo figurativo de esta índole podría justificarse. En más de una ocasión, incluso en este mismo trabajo, se ha hecho hincapié en el valor político de la moneda ${ }^{55}$, pero a veces parece olvidarse que también es transmisora de un mensaje religioso y por tanto conlleva un valor espiritual.

Ha quedado constancia de cómo las monedas andalusíes eran frecuentemente perforadas $\mathrm{y}$, desde mi punto de vista, el argumento más sólido para explicar estas perforaciones es el de su uso como colgantes y amuletos ${ }^{56}$. Esta función protectora de la moneda ${ }^{57}$ se fundamenta en las leyendas de carácter religioso en ella grabadas: la šahäda y los textos coránicos, así como fórmulas de testimonio de fe (لا اله الا اله وحده لا شـريـك له). Estas leyendas se pueden utilizar con un valor mágico ya que no hay que olvidar que las diversas aleyas del Corán aportan soluciones y remedios a todos los problemas que se le plantean al ser humano en su vida cotidiana. Es más, se ha llegado a afirmar que «la magie musulmane ne peut être orthodoxement qu'une magie "coranique" $" 58$.

${ }^{54}$ Ibn 'Idārī, op. cit., 109-111. Clément, F., op. cit., 167.

55 Sirvan como ejemplo Guichard, P., La España Musulmana. Al-Andalus Omeya (siglos VIII-XI), Historia de España, vol. VII, Madrid, 1995; y Wasserstein, D. J., The Caliphate in the West, 72. Pero, como cuestioné anteriormente, ¿por qué si no se había introducido antes un símbolo iconográfico relativo a un acontecimiento político o militar habría de introducirse ahora?

${ }^{56}$ Los primeros trabajos que abordaron con detenimiento la problemática de las monedas perforadas fueron Canto García, A., «Perforations in coins of the Andalusian Umayyad Caliphate: A form of Demonetization?», Problems of Medieval Coinage in the Iberian Area, II, Avilés, 1986, 345-360 e Ibrāhìm, T., «Notas sobre un amuleto andalusí y la problemática de las monedas perforadas», Boletín de Arqueología Medieval, 2 (1988), 137-140.

57 Función protectora como amuleto, no como talismanes, ya que estos últimos requieren una elaboración compleja que les transfiera sus cualidades mágicas. Véase al respecto Kalus, L., Catalogue des cachets, bulles et talismans islamiques, Paris, 1981, 70, que sigue la definición ya dada por Marquès-Rivière, J., Amulettes, talismans et pentacles, Paris, 1938. Sobre los amuletos y talismanes en el Islam, consúltese también Ruska, J., Carra de Vaux, B. «Tilsam», $E I^{2}$; Fahd, T., «Tamima», EI ; Akhemisse, M., Médicine, Magie et Sorcellerie au Maroc, Casablanca, 1985; Kalus, L., Catalogue of Islamic Seals and Talismans, Oxford, 1986; y Fodor, A., Amulets from the Islamic world, Budapest, 1992.

58 Marquès-Rivière, J., op. cit., 129; Doutté, E., Magie \& Religion dans l'Afrique du Nord, Paris, 1994, 211. Sobre el carácter sagrado de las leyendas numismáticas islámicas 
Es sabido que en el siglo V/XI, «los andalusíes eran supersticiosos y creían por ejemplo en el mal de ojo»; y esta actitud vital no era patrimonio exclusivo de la 'āmma, sino que también afectaba a la jāșșa ${ }^{59}$. Así, parece ser que era bastante común la costumbre de llevar encima un sello personal; algunos de ellos se realizaban sobre metal blanco, otros sobre gemas a las que se le atribuían virtudes mágicas específicas, que conferían así al sello una función protectora que hacía de él una suerte de amuleto. Se conservan no pocos sellos y talismanes, tanto medievales como posteriores, que se pueden considerar ší'íes por sus referencias a 'Alī y a los doce imämes. Y al igual que sucede hoy en día, amuletos y talismanes servían al mismo tiempo de objeto protector y de joya ${ }^{60}$.

Además, es sabido que durante el siglo V/XI hubo una «liberación de la presión religiosa que se había venido ejerciendo en siglos anteriores» ${ }^{61} \mathrm{y}$, qué duda cabe, el califato de 'Alī b. Hammūd fue el preludio a esta época. Sabemos asimismo que, aunque fuera escasa, la difusión del š̄íísmo en al-Andalus está directamente relacionada con las influencias beréberes y, las referencias a él en las fuentes, especialmente vinculadas con los zīríes y con los ḥammūdíes. Si bien carecemos de datos que puedan hacer pensar que estos últimos propugnasen doctrinas o prácticas šî́íes, parece que se desarrolló en al-Andalus una corriente de «respeto y reverencia por los descendientes de 'Alī y Fāțima»» ${ }^{62}$. Así pues, las doctrinas šî'íes, incluso las más extremas, fueron conocidas en al-Andalus ${ }^{63}$.

También sabemos que el sexto imām, Ŷa'far al-Ṣādiq, es reconocido en el Islam en general - no solamente en ambientes šííies - y sobre todo en el Magreb, por su vinculación a la magia, el esoterismo y la alquimia y que se le atribuyen numerosas obras

\footnotetext{
véanse también Christensen, A., Xavāss -i-āyāt. Notices et extraits d'un manuscrit persan traitant la magie des versets du Coran, Copenhague, 1920; y Vega Martín, M., Peña Martín, S., «La mejora epigráfica del 229 H.: sentido y forma en las leyendas del dirham emiral», IV Jarique de Numismática Andalusí, 121-134.

59 Fierro, M. I., «La religión», 409.

${ }^{60}$ Kalus, L., Catalogue des cachets, 7- 11, 32-35, 52 y 69-73. Sobre la costumbre de llevar amuletos véase también Pareja, F. M. ${ }^{\text {a }}$, La religiosidad musulmana, Madrid, 1975, 210-211.

${ }^{61}$ Fierro, M. I., «La religión», 433.

62 Ibidem, 435.

${ }^{63}$ Ibidem, 436-437.
} 
de adivinación, por la cualidad que se le reconocía de predecir el futuro ${ }^{64}$. Aunque a la dinastía hammūdí no se la pueda considerar una «secta» ší'í, en mi opinión, bien pudieron estar sujetos a estas influencias.

Por otro lado, es sabido que el pez es considerado un animal benéfico debido tanto a su importancia en la dieta, como se ha señalado antes, cuanto a sus utilidades, bien prácticas —en relación con la vida cotidiana incluso en el desierto-, bien medicinales y afrodisíacas ${ }^{65}$. El pez da nombre a numerosas estrellas y es además un signo zodiacal (burŷ al-hüt); signo asociado al planeta Venus, planeta asociado al amor en la magia talismánica. Además, el pez representa el agua y la lluvia y, por consiguiente, la fertilidad y la prosperidad ${ }^{66}$. En Emesa (Hims), lugar de origen del contingente sirio que recibiera concesiones para instalarse en el área del Guadalquivir, y donde ya se acuñaban feluses con peces contemporáneamente a la conquista de la Península Ibérica ${ }^{67}$, podemos encontrar, cerca de la Gran Mezquita, la representación figurativa de un pez con un claro valor talismánico ${ }^{68}$. Más concretamente, en el Norte de África, de Egipto a Marruecos, zonas de importante actividad pesquera, el pez es un motivo decorativo recurrente debido a las cualidades protectoras que se le atribuyen: se considera que aleja las fuerzas del mal, protege a los recién nacidos de las envidias, preserva la intimidad del hogar y favorece las uniones ${ }^{69}$.

Conocemos sellos y talismanes anteriores al siglo VII/XIII con representaciones figurativas animales (león, gacela, escorpión, caba1lo...) ${ }^{70}$; y de las pocas representaciones figurativas zoomórficas que podemos encontrar en la joyería tradicional marroquí, aparece la figu-

${ }^{64}$ Libro de dichos maravillosos (Misceláneo morisco de magia y adivinación), Introducción, glosarios e índices por A. Labarta, Madrid, 1993, 0.21-0.22 y 0.28.

65 Viré, F., op. cit., 1022-1023. Sobre ictionimia en al-Andalus véanse los trabajos de Torres, M. ${ }^{2}$ P., «La ictionimia en el "vocabulista" de Alcalá», Ciencias de la Naturaleza en al-Andalus, 1, Granada (1990), 43-56 e «Ictionimia en glosarios andalusíes», Al-Andalus y el Mediterráneo, Barcelona-Madrid, 1995, 227-241.

66 Jereb, J. F., Arts and Crafts of Morocco, Londres, 1995, 19.

67 Recuérdese lo indicado anteriormente al respecto en este artículo (cf. 217).

${ }^{68}$ Elisseeff, N., «Emesa», $E I^{2}$.

69 Incluso en Marruecos, una expresión popular hace del pez una bendición: «al-hūt fi-hi al-rizq» («el pescado es nuestro sustento»). Véase Chebel, M., Dictionnaire des symboles musulmans. Rites, mystique et civilisation, Paris, 1995, 344-345.

70 Kalus, L., Catalogue des cachets, 7-11, 70-73 y 93. 
ra del pez asociada, siempre y en exclusiva, a amuletos, y no con otro tipo de joyas como puedan ser las utilizadas en las ceremonias matrimoniales ${ }^{71}$.

Pero, además, sabemos que «'Alī b. Ḥammūd daba el mal de ojo. Apenas abría sus ojos sobre algo que encontraba hermoso que se precipitaba el daño sobre ello. Le ocurrieron en eso casualidades extrañas. Se cuenta que le dijo a la [más] apreciada de sus mujeres "Oculta tus gracias de mí lo que puedas, pues ciertamente estoy preocupado por ti a causa de mi mal de ojo, y yo quiero gozar largamente de ti" ${ }^{72}$. Por mucho que se trate de una anécdota, probablemente más orientada a perjudicar la imagen del califa que a favorecerla, ya el hecho de que sea recogida y referida con detalle me parece significativo. Del texto se desprende que "Alī estaba afectado por ello y su ánimo albergaba la intención de hacer lo posible por evitarlo.

A la vista de todo lo anterior, ¿parecería tan descabellado pensar que la introducción de peces en el cuño de sus monedas pueda responder a una simbología mágico-espiritual? 'Alī b. Hammūd bien pudo estar inmerso en una concepción del mundo condicionada por lo esotérico, y no sólo en la misma medida en que lo pudiera estar cualquiera de sus contemporáneos, sino más aún si cabe, por las influencias beréberes y šīíes del ambiente del que provenía. Es decir, la introducción del símbolo del pez podría responder a los deseos del califa de protegerse contra el mal de ojo y de atraer al mismo tiempo la prosperidad a su imāmato en un momento crítico en el que la población de Córdoba vuelve a estar muy descontenta con su política favorable a los beréberes.

No obstante, esta función protectora no tiene sólo una dimensión puramente "mágica»: existe la posibilidad de hacer una lectura interpretativa de la iconografía del pez en relación al texto sagrado. En cuatro ocasiones se hace referencia a los peces en el Corán. La primera de ellas, indirecta, hace alusión a lo lícito de la pesca, poniendo de relieve lo agradable que resulta el consumo de pescado (Qur'ān V, 97). Las otras tres ocasiones hacen referencia, esta vez

${ }^{71}$ Rabaté, M.-R., Goldenberg, A., Bijoux du Maroc. Du Haut Atlas à la Méditerranée. Depuis le temp des juifs jusqu'à la fin du XX $X^{e}$ siècle, Aix-en-Provence, 1999, 130, 172,188 y 197.

72 Ibn 'Iḍārī, op. cit, 110-111. 
directa, al pez en sí y, significativamente, le sitúan en el papel protagonista de un suceso milagroso (Qur'ān VII, 163; XVIII, 60-63 y XXXVII, 139-148). Dos de estos tres milagros están relacionados, en mayor o menor grado, con la figura del profeta Moisés; el tercero, con la del profeta Jonás, conocido también como el «hombre del pez» (șăhib al-ḥūt o $\underline{d} \bar{u}$ 'l-nūn $)^{73}$, cuyo nombre da título a la décima azora de El Corán. Al respecto, es muy destacable el hecho de que se considere a los profetas como el símbolo de la intercesión ante Dios ${ }^{74}$. Es más, en la tradición š̄íí también podemos encontrar peces protagonizando algún hecho milagroso. Baste con citar aquel en el que los peces saltaron del agua para saludar a 'Alī b. Abī TTālib como Príncipe de los Creyentes, cuando éste obró el milagro de retroceder las aguas del desbordado Éufrates salvando a la amenazada ciudad de Kufa ${ }^{75}$.

Por tanto, considero que la introducción de la representación figurativa del pez en el cuño de las monedas del 'alawí bien podría responder, más que a la esfera de lo material, a la de la espiritualidad. Es decir, más que ser el testimonio de la existencia de una mayor o menor abundancia pesquera en una zona geográfica concreta, el pez tendría un valor espiritual marcadamente propiciatorio.

\section{Catálogo de los ejemplares con peces del 408/1017-1018}

Debido a que todos los ejemplares son del mismo año y ceca, el orden de presentación de los mismos responde exclusivamente al criterio ponderal. En la descripción de cada pieza se incluye, en la primera línea, el año, materia, peso (expresado en gramos), módulo (expresado en milímetros), posición del cuño (expresado en horas), y alteraciones en caso de haberlas; en la segunda línea se encuentran las referencias tipológicas ordenadas cronológicamente; en un tercer renglón, la localización y registro del ejemplar; en cuarto lugar, las leyendas marginales; para finalizar con un apartado destinado a las observaciones.

${ }^{73}$ Qur'ān LXVIII, 48 y XXI, 87 respectivamente.

74 Chebel, M., op. cit., 352.

75 Kitäb al-Irshad (The Book of Guidance into the Lives of the Twelve Imams) by Shaykh al-Mufid, trad. I. K. A. Howard, Londres, 1981, 263. 
Las siglas y abreviaturas utilizadas en el presente trabajo son, por orden alfabético, las siguientes:

\begin{tabular}{|c|c|}
\hline A.N.S. & $=$ American Nun \\
\hline AR & $=$ plata \\
\hline Ceuta & $\begin{aligned}= & \text { Rodríguez Lorente, J. J., Ibrāhīm, T., Numismática de } \\
& \text { Ceuta Musulmana, Madrid, } 1987 .\end{aligned}$ \\
\hline Codera & $\begin{aligned}= & \text { Codera, F., «Estudio crítico sobre la historia y mone- } \\
& \text { das de los Hammudíes de Málaga y Algeciras», Museo } \\
& \text { Español de Antigüedades, VIII (1877), 421-469. }\end{aligned}$ \\
\hline Delgado & $\begin{aligned}= & \text { Láminas inéditas de D. Antonio Delgado, J. J. Rodríguez } \\
& \text { Lorente y T. Ibn Ḥāfiz Ibrāhīm (eds.), Madrid, } 1985 .\end{aligned}$ \\
\hline I.A. & = Primera área (anverso) \\
\hline I.M. & $=$ Primer margen $\mathrm{u}$ orla \\
\hline II.A. & = Segunda área (reverso) \\
\hline II.M. & $=$ Segundo margen $\mathrm{u}$ orla \\
\hline IV Jarique & $\begin{aligned} \text { = Ibrāhīm, T., «El dinar andalusí. Nuevas aportaciones», } \\
\\
\text { IV Jarique de Numismática Andalusí, A. Canto y V. } \\
\text { Salvatierra (eds.), Jaén, 2001, 34-51. }\end{aligned}$ \\
\hline M.A.N. & $=$ Museo Arqueológico Nacional \\
\hline M.C.M. & $=$ Museo Casa de la Moneda \\
\hline Miles & $\begin{aligned}= & \text { Miles, G. C., Coins of the Spanish Mulük al-Tawà'if, } \\
& \text { Nueva York, } 1954 .\end{aligned}$ \\
\hline Prieto & $\begin{aligned}= & \text { Prieto y Vives, A., Los Reyes de Taifas. Estudio histó- } \\
& \text { tico-numismático de los musulmanes españoles en el } \\
& \text { siglo V de la Hégira (XI de J.C.), Madrid, } 1926 .\end{aligned}$ \\
\hline Viv & $\begin{aligned}= & \text { Vives y Escudero, A., Monedas de las dinastías arábi- } \\
& \text { go-españolas, Madrid, } 1893 .\end{aligned}$ \\
\hline
\end{tabular}




\section{Año 408/1017-1018}

Madīnat Sabta

Dirham

I.A.

II.A.

$$
\begin{aligned}
& \text { لا اله الا } \\
& \text { الله وحده } \\
& \text { لا شريـك له }
\end{aligned}
$$

$$
\begin{aligned}
& \text { ولي العهد } \\
& \text { الامام علي } \\
& \text { اميـر المؤمسنين } \\
& \text { النـاصر لديـن الله } \\
& \text { بسحيى }
\end{aligned}
$$

1. [40]8. AR, 3,4 gr., $23 \mathrm{~mm} \varnothing, 02: 00 \mathrm{~h}$.

Vives 731, Prieto 62b, Miles -.

M.A.N. 63.74 .

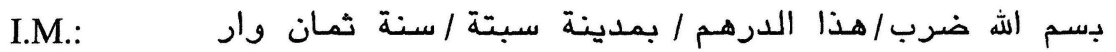

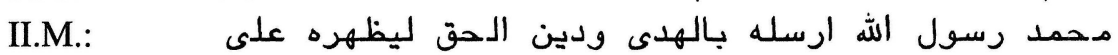

Observaciones: Leyenda del I.M. distribuida en cuatro segmentos. Dos peces en la I.A. (similar a la del n. ${ }^{\circ} 2$ y n. ${ }^{\circ} 6$ del presente catálogo) y otros dos en la II.A.

2. [40]8. AR, 3,1 gr., $23,5 \mathrm{~mm} . \varnothing, 1: 00 \mathrm{~h}$.

Vives 731, Prieto 62b, Miles -

Colección F. Benito de los Mozos.

I.M.:

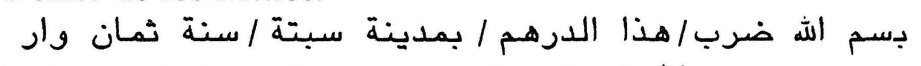

II.M.:

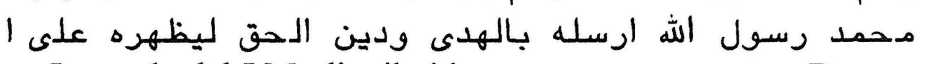

Observaciones: Leyenda del I.M. distribuida en cuatro segmentos. Dos peces en la I.A. (similar a la del n. ${ }^{\circ} 1$ y n $^{\circ}{ }^{\circ} 6$ del presente catálogo). II.A. similar a la del ejemplar publicado por Codera (n. ${ }^{\circ} 8$ del presente catálogo).
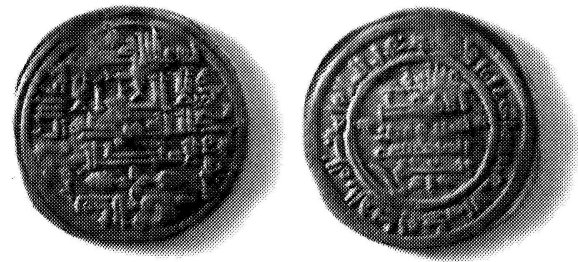
3. [40]8. AR, 2,9 gr., $22,5 \mathrm{~mm} . \varnothing$

Vives 731, Prieto 62b, Miles 30, Ceuta, 38.

Colección particular.

I.M.:

(.... بمدينة سبتة سنة ثمان ورار

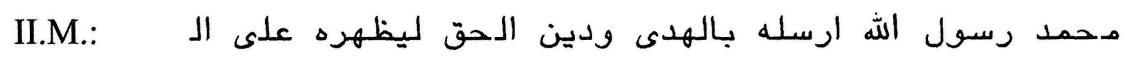

Observaciones: Primer cuarto de la leyenda del I.M. rectilineal. Dos peces en la I.A. y dos en la II.A. Similar a Miles 30 (n..$^{\circ}$ del presente catálogo). Ejemplar publicado en Ceuta, 1987.
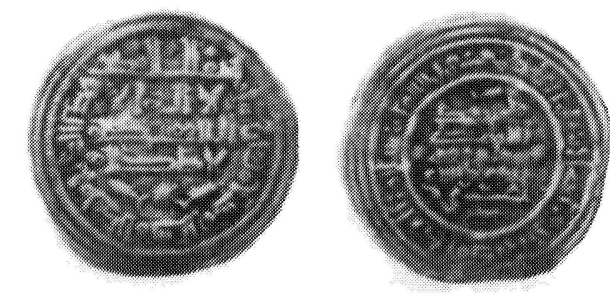

4. [40]8. AR, 2,83 gr., $24 \mathrm{~mm} . \varnothing$

Vives 731 , Prieto $62 \mathrm{~b}$, Miles 30 , Ceuta 38 .

A.N.S. 1928.999 .112

I.M.:

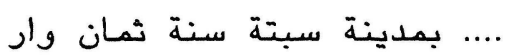

II.M.: محمد رسول الله ارسله بالهدى ودين الحق ليظهزه على الـ

Observaciones: Primer cuarto de la leyenda del I.M. rectilineal. Dos peces en la I.A. y dos en la II.A. Similar a Ceuta, 38 (n..$^{\circ} 3$ del presente catálogo). Ejemplar publicado en Miles, 1954 (Lámina 1).
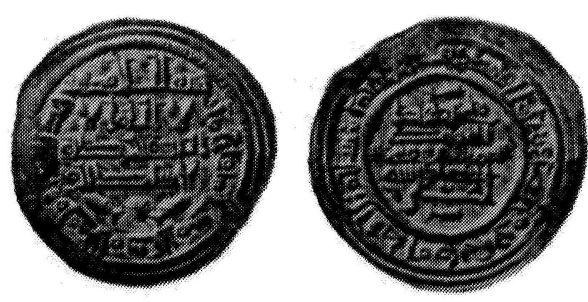

5. [40]8. AR, 2,51 gr., $23 \mathrm{~mm} . \varnothing, 12: 00 \mathrm{~h}$.

Vives 731 , Prieto $62 \mathrm{~b}$, Miles - .

M.A.N. 63.78

I.M.:

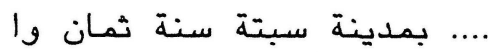

II.M.: محمد رسول الله ارسله بالهدى ودين الحق ليظهره على الدين 
Observaciones: Primer cuarto de la leyenda del I.M. rectilineal. Cuatro peces en la I.A. y dos en la II.A. Ejemplar muy similar a Delgado n. ${ }^{\circ}$, lámina VIII (véase el n. ${ }^{\circ} 7$ del presente catálogo).

6. [40]8. AR, 1,72 gr., 18’25 mm. $\varnothing, 11: 00$ h. Recortada.

Vives 731, Prieto 62b, Miles -.

Colección particular.

I.M.:

بسم الله ض[رب]/[...]/ [...]/ [سن]ة ثمان وار

II.M.:

[محمد ر]سول الله ارسله [...]

Observaciones: Leyenda del I.M. distribuida en cuatro segmentos. Dos peces en la I.A. que es similar a la del $n^{\circ} 1$ y a la del $n^{\circ} 2$ del presente catálogo.

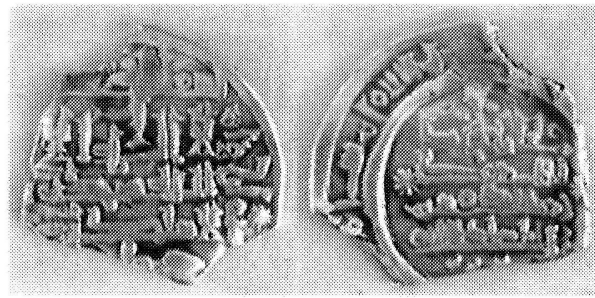

7. [40]8. AR.

Delgado n. ${ }^{\circ}$ 1, Lámina VIII, Ceuta, 39.

I.M.:

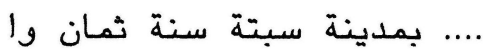

II.M.: محمد رسول الله ارسله بالهدى ودين الحف ليظهره على الدين

Observaciones: Primer cuarto de la leyenda del I.M. rectilineal. Cuatro peces en la I.A y dos en la II.A. Ejemplar muy similar al M.A.N. 63.78 (n. ${ }^{\circ} 5$ del presente catálogo), lo que hace pensar que pueda tratarse de un dibujo de dicho ejemplar ${ }^{76}$. No obstante, al no tener certeza al respecto, ha de considerarse como un ejemplar diferente. Publicado en Láminas inéditas de A. Delgado (1985) y Ceuta (1987).
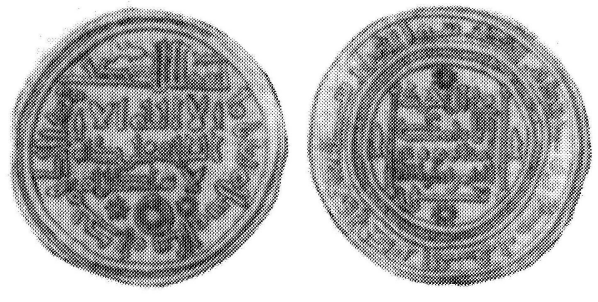

${ }^{76}$ Sobre el método de elaboración de las láminas de Delgado véase Delgado, A., Estudios de Numismática Arábigo-Hispana, XVIII. 
8. [40]8. AR.

Codera n. ${ }^{\circ} 6$, Lámina I.

¿Colección particular?

I.M.:

ا..... بمدينة سبتة سنة ثمان وانة والة المانة

II.M.:

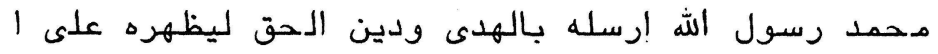

Observaciones: Primer cuarto de la leyenda del I.M. rectilineal. Tres peces en la I.A. II.A. similar a la del ejemplar . $^{\circ} 2$ del presente estudio. En el momento de su publicación en Codera, «Estudio crítico...» (1877) este ejemplar pertenecía a la colección del Sr. D. Antonio Cabré, si bien desconozco su paradero actual.

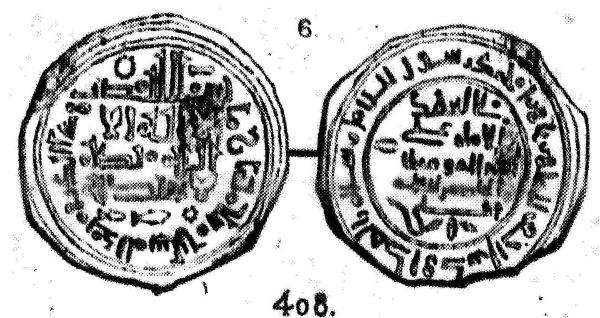

408.

\section{RESUMEN}

En el presente artículo se analizan las emisiones del año 408/1017-1018 que llevara a cabo 'Alī b. Hammūd, primer califa de la dinastía ḥammūdí en al-Andalus. Se ha prestado especial atención al análisis de las leyendas monetales y a su relación con diversos aspectos relativos a la legitimidad de dicha dinastía. Asimismo, se ha estudiado la presencia del motivo figurativo del pez en una de las series de este año y se ha sugerido una serie de hipótesis interpretativas y líneas de investigación que puedan llevarnos a un mejor conocimiento de la numismática hammūdí. Para finalizar, se incluye el catálogo de los ejemplares con peces del año 408/1017-1018.

\section{ABSTRACT}

This article analyzes the coins issued by 'Alī b. Hammūd, the first caliph of the Hammüdi dynasty in al-Andalus, in the year 408/1017-1018. Special attention has been given to the analysis of monetary legends and their relation with different aspects of legitimation of the dynasty. The images of fish depicted in one of the series of coins has been studied and a number of hypotheses have been suggested, to provide a deeper knowledge of Ḥammūdi numismatic. Finally, the article includes a catalogue of the coins decorated with fish figures from that year. 